\title{
Gaenslen's Split Heel Approach for the Treatment of Chronic Osteomyelitis of the Calcaneus: A series of three
}

\section{cases}

\author{
by Arunangsu Bhattacharyya, MS(Ortho) ${ }^{1 \rrbracket}$, Rana Das, MS(Ortho) ${ }^{2}$
}

The Foot and Ankle Online Journal 3 (11): 3

Background: Osteomyelitis of the calcaneum with non-healing ulcer is an old but challenging entity to orthopaedic surgeons. Acute osteomyelitis is treated by intravenous antibiotics and drainage. There are different surgical procedures to manage chronic osteomyelitis of calcaneum i.e. partial, total calcanectomy, split heel approach and vascularized flaps to cover the ulcer. In this reported series, the split heel approach has been adopted as a safe procedure with an excellent outcome in selected cases.

Materials and Methods: A series of three cases including different age group and sex characteristics with osteomyelitis of the calcaneus are reported. All patients underwent the split heel approach to address the osteomyelitis.

Results: All three cases healed with a thin scar over the planter surface of heel and it was painless on walking after follow up of almost four years without recurrence of osteomyelitis.

Conclusions: The split heel approach is an excellent, easy and safe way of management for chronic osteomyelitis of calcaneum with a centrally located ulcer in selected cases.

Key words: Split heel approach, osteomyelitis of calcaneum, non-healing ulcer.

This is an Open Access article distributed under the terms of the Creative Commons Attribution License. It permits unrestricted use, distribution, and reproduction in any medium, provided the original work is properly cited. @The Foot and Ankle Online Journal (www.faoj.org)

$\mathrm{T}$ he calcaneum is involved in $7 \%$ to $8 \%$ of all cases of Osteomyelitis. ${ }^{1}$ The introduction of the split heel technique in the treatment of calcaneal osteomyelitis was first described by Gaenslen in $1931 .^{2}$ The calcaneum is invested by closely adhered periosteum over which muscles are attached. As the result of osteomyelitis, pus collected within the bone cannot strip the periosteum and go underneath it. Thus, cortical bone does not get avascularized and characteristically involucrum is also not formed. Here the periosteum is more commonly perforated than stripped off. ${ }^{2}$

Address correspondence to: Dr Arunangsu Bhattacharyya,MS(ORTHO) A-8/4,Bidhan Abasan,Block-FB,Sector-3,Saltlake,Kolkata-700097.West Bengal,India. Email: orthoarunangsu@yahoo.com .

\footnotetext{
${ }^{1}$ Assistant Professor,Dept. of orthopaedics, Medical college, Kolkata.

${ }^{2}$ Associate Professor, Dept. of orthopaedics, Medical college, Kolkata.
}

Therefore, a usual draining sinus is formed over the heel with osteomyelitis of the calcaneum. The sinus may be located over the plantar, medial or lateral surface of heel. The split heel approach was performed in this series in properly selected cases with ulcer over the heel and almost centrally located osteomyelitic cavity within the calcaneum.

In 1976, Broudy opined this technique of Gaenslen as indicated for refractory cases of osteomyelitis with draining sinus centrally located on the plantar aspect of the heel and requiring extensive debridement. 

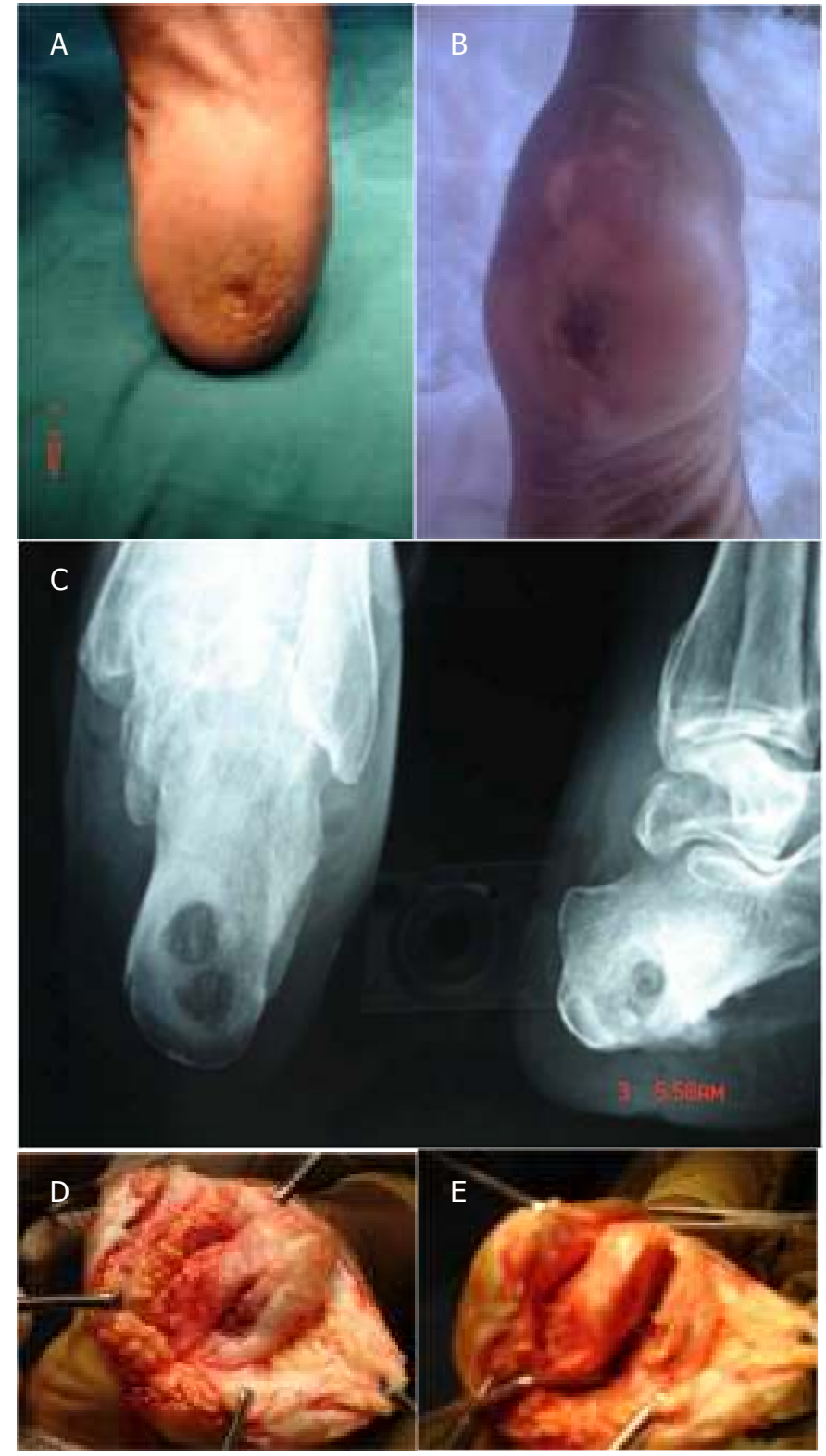

Figure1 Case No 1: Discharging sinus over plantar surface of heel before surgery. (A) The postoperative photograph showing a well healed surgery with a thin healed scar. No recurrent ulcers or discharge is seen. (B) Preoperative axial and lateral views of calcaneum showing two lytic areas at different levels within the center of the calcaneus. (C) Steps of surgery show heel is split longitudinally. ( $D$ and $E$ )
The traditional approach, either medially or laterally, could only provide limited exposure of the affected calcaneus. ${ }^{3}$ The split heel technique has the advantage of allowing for adequate exposure of the extensive lesion in the calcaneus. ${ }^{2}$

Hence, the split heel approach was the preferred technique and the calcaneum was split to reach the centre of affected cancellous portion of bone to be effectively removed by curettage.

\section{Materials and Methods}

There were three cases reported in this series. All cases were followed up for minimum three years. One male of 51 years, one female of 32 years and a male child of three years and two months were included in this study. This study was followed for a duration of more than four years (i.e. from 2006 to 2010). Ethical committee permission was granted for this study and consent of patients was also taken during the study. All three patients were affected with chronic osteomyelitis of calcaneum. The main criteria for selection of cases was centrally located lesion of osteomyelitis within calcaneum with discharging sinus over the planter surface of heel. None of the patient's had diabetes.

Talo-calcaneal and other foot joints were not involved in any case. All three cases were operated with split heel approach of Gaenslen. Pneumatic tourniquet was used to render the operative field bloodless. With the patient lying prone and a support under the ankle, an incision was made starting on the plantar surface of the foot directly opposite the tuberosity of the fifth metatarsal bone, on a line bisecting the heel and the middle toe. It was then extended over the heel and ended after splitting the Achilles tendon in the lower three or four centimeters. This incision was through the skin and plantar aponeurosis and in between abductor digiti quinti and flexor digitorum brevis. The lateral plantar artery and nerve were placed at the distal end of incision. The quadratus plantae fibers were exposed and split longitudinally. 

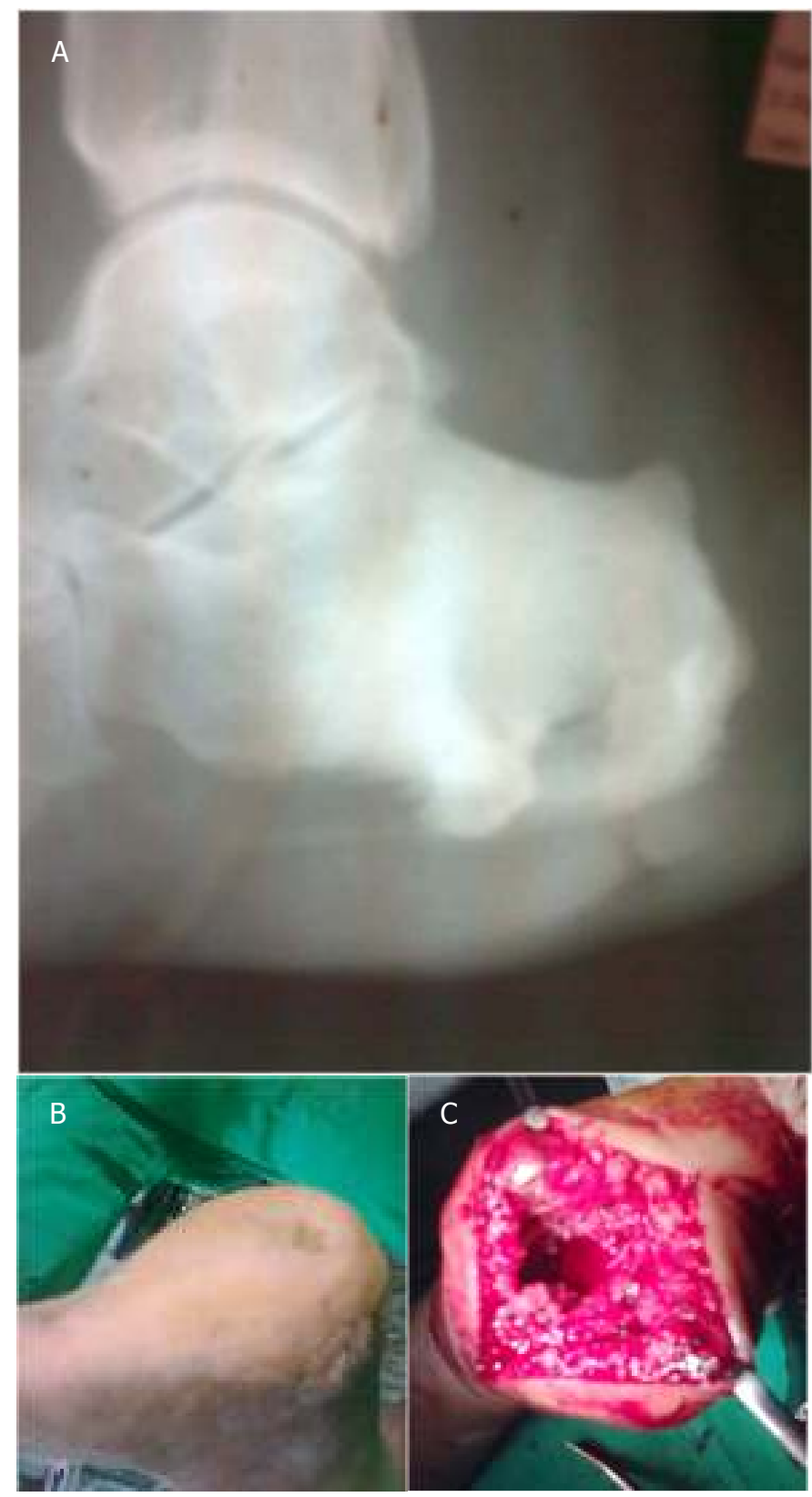

Figure 2 Case No 2: Preoperative view shows a large destructed area of osteomyelitis within the calcaneus. (A) Preoperative clinical photograph shows centrally placed ulcer over heel. (B) Perioperative photograph shows split heel approach and a large cavity of osteomyelitic bone within the calcaneus. (C)
The calcaneum was then bisected longitudinally starting from behind upwards and forwards with osteotome up to the upper end of the infected area. Infected bone was curetted through the cortex and sent for Histo-Pathological Examination (HPE) and culture to detect causative organism. Negative suction drain was used in each case and wound was closed with intermittent stitches. The limb was rested in plaster of paris (POP) splint for three weeks. Wound was dressed regularly every two days during the week.

\section{Case Reports}

\section{Case One}

A 51 year old male who usually walks barefooted presents with a painless ulcer over planter surface of left heel for eight months. (Fig. 1A and 1B)He had been treated by oral antibiotics and multiple insufficient surgeries. Radiograph showed osteomyelitis of calcaneum with two lytic areas in central location. (Fig. 1C) The erythrocyte sedimentation rate (ESR) was high and he was nondiabetic.

Surgical intervention involved a split heel approach, calcaneum was bisected and infected material was curetted out. (Fig. 1D and 1E) Tissue was sent for Histo Pathological Examination (HPE) and culture for infective organism. Wound was irrigated with amikacin and closed with intermittent stitches with a negative suction drain inside. Limb was supported in plaster slab for 3 weeks. Drain was removed after 48 hours. HPE was reported as chronic osteomyelitis and infective organism was Staph.aureus coagulase positive sensitive to Amoxycillin and Clavulinic acid. Antibiotics were continued for six weeks. Wound was dressed on two days in a week for four weeks. Wound healed with painless thin scar (Figure 1D). The reported case was allowed to weight bear on the affected heel at the end of three months and at follow up for four and half years without recurrence but with a mild limp. 

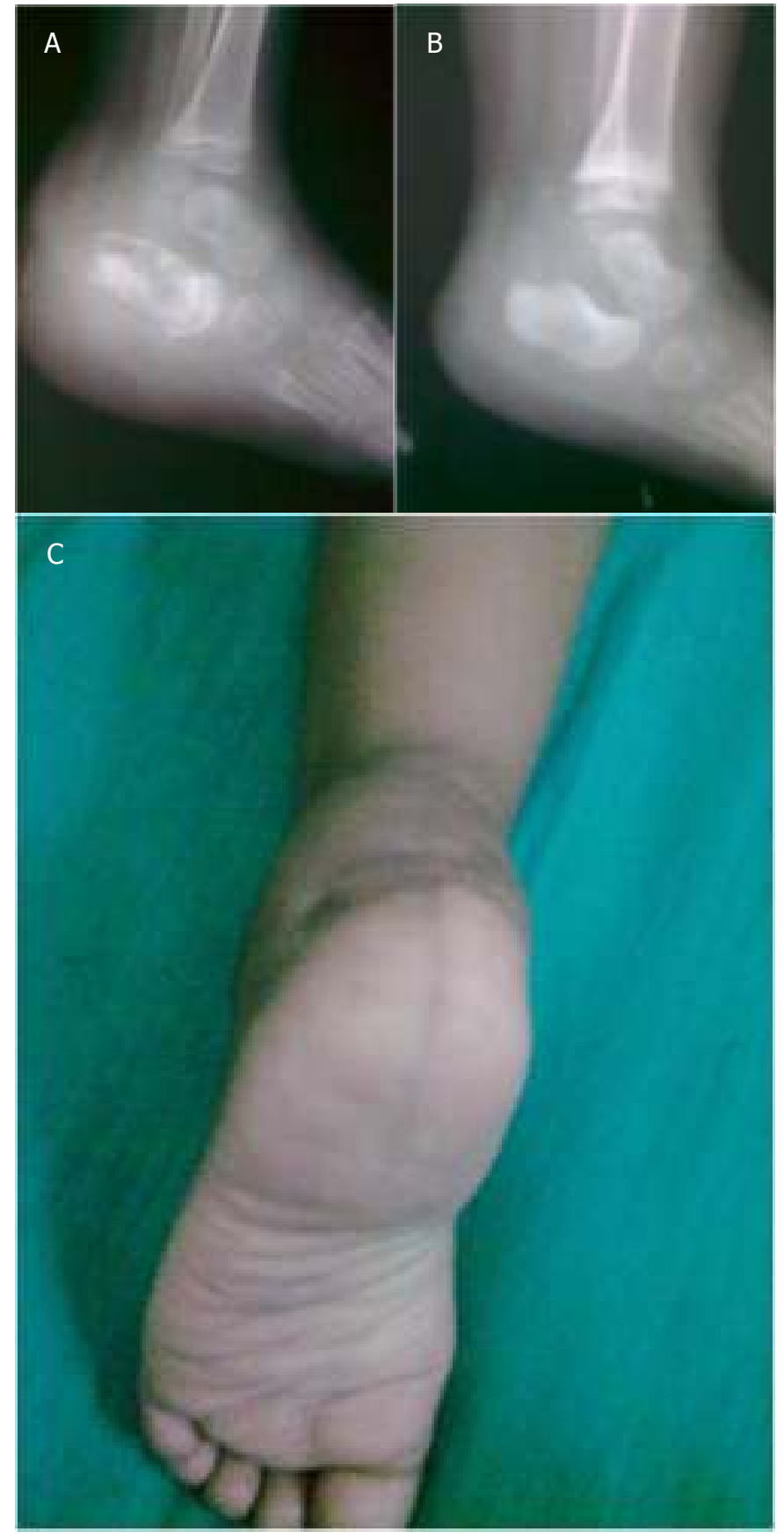

Figure 3 Case No 3: Preoperative radiograph shows gross involvement of calcaneus with osteomyelitis (A) Follow up radiograph after almost one year of surgery shows healed calcaneus. (B) Clinical photograph shows thin healed scar one year after surgery. (C)

\section{Case Two}

A female of 32 years of poor socio-economic group presented with discharging sinus over right heel of almost four years (Fig. 2B). It was too painful to sleep at night. There were sinuses at two different locations over heel, one at central and other at lateral or outer side of the heel. ESR was high. Radiographs showed large involved lytic area within calcaneum with osteomyelitis. (Fig. 2A) She underwent surgery using a Gaenslen's split heel approach. There was large cavity inside the calcaneum. (Fig. 2C) which was thoroughly cleaned with curette and washed with amikacin mixed normal saline. The wound was closed with intermittent stitches and other steps of follow up were similar to the first reported case. In this case, the wound healed earlier and recovery was uneventful with a minimum painless scar which was not involuted in as reported in other series ${ }^{2}$. At follow up of over four years she reports with no pain up or recurrence of disease.

\section{Case Three}

A three years and two months old male child was suffering from pain and swelling of left heel for nearly four months. He was having fever regularly. There was a discharging sinus over his heel and his heel was tender on palpation. Peripheral blood showed high lymphocyte count and high ESR. Radiographs were almost definitive of chronic osteomyelitis of calcaneum which was grossly involved (Fig. 3A). The heel was explored with split heel approach and infected caseated tissue was biopsied and sent for HPE and culture to detect causative organism. The wound was closed with a small drain inside and limb was immobilized in plaster slab for three weeks.

HPE and tissue culture both confirmed the diagnosis as tubercular osteomyelitis. Anti tubercular chemotherapy continued for nine months. Follow up radiographs showed recovery from osteomyelitis. (Fig. 3B) and the wound also healed with a thin painless scar. (Fig. 3C) 


\begin{tabular}{|c|c|c|c|c|c|c|c|c|}
\hline & $\begin{array}{l}\text { Age } \\
\text { (yrs) }\end{array}$ & Sex & $\begin{array}{l}\text { Route of } \\
\text { infection }\end{array}$ & $\begin{array}{l}\text { Causative } \\
\text { organism }\end{array}$ & $\begin{array}{l}\text { Extent of } \\
\text { disease }\end{array}$ & $\begin{array}{l}\text { Month } \\
\text { of } \\
\text { surgery }\end{array}$ & $\begin{array}{l}\text { Month } \\
\text { of } \\
\text { wound } \\
\text { healing }\end{array}$ & Results \\
\hline $\begin{array}{l}\text { Case } \\
\text { no } 1\end{array}$ & 51 & Male & Thorn pick & $\begin{array}{l}\text { Staph. } \\
\text { aureus(coag+ve) }\end{array}$ & $\begin{array}{l}\text { Two lytic } \\
\text { areas } \\
\text { vertically } \\
\text { placed }\end{array}$ & $\operatorname{Dec}^{\prime} 05$ & Feb'06 & $\begin{array}{l}\text { Thin scar, } \\
\text { mild limp,no } \\
\text { ulcer,no } \\
\text { recurrence }\end{array}$ \\
\hline $\begin{array}{l}\text { Case } \\
\text { no } 2\end{array}$ & 32 & Female & Trauma & $\begin{array}{l}\text { Staph. } \\
\text { aureus(coag+ve) }\end{array}$ & $\begin{array}{l}\text { Large } \\
\text { destructed } \\
\text { area within } \\
\text { calcaneum }\end{array}$ & July'06 & August'06 & $\begin{array}{l}\text { Thin,painless } \\
\text { scar,no } \\
\text { recurrence }\end{array}$ \\
\hline $\begin{array}{l}\text { Case } \\
\text { no } 3\end{array}$ & 3yrs2mnths & $\begin{array}{l}\text { Male } \\
\text { child }\end{array}$ & Haematogenous & $\begin{array}{l}\text { Mycobacterium } \\
\text { Tuberculosis }\end{array}$ & $\begin{array}{l}\text { Gross } \\
\text { involvement } \\
\text { of whole } \\
\text { body of } \\
\text { calcaneum }\end{array}$ & Jan'07 & Feb'07 & $\begin{array}{l}\text { Very } \\
\text { thin,almost } \\
\text { painless } \\
\text { scar,No } \\
\text { recurrence } \\
\text { yet }\end{array}$ \\
\hline
\end{tabular}

Table 1 Different age groups with chronic osteomyelitis of calcaneum with various route of infection, healing periods and final outcome.

\section{Results}

All three patients are of different age group and under follow up for almost four years. They all recovered from the disease almost completely without any untoward complication. The foot of the affected child showed no shortening or deformity after almost three years of follow up. Scarring was thin and painless on walking. The sinus tracts were completely healed. The heel shape was maintained in all cases. Follow up radiograph films showed signs of healing of bony lesion within calcaneum.

Range of movement of the ankle and other joints of foot was maintained. The most common organism detected was staphylococcus. aureus. The child was affected with tubercular osteomyelitis. Table one has demonstrated the various route of infection and the healing periods and final outcome of all three cases. (Table 1)

\section{Discussion}

In the original series reported by Gaenslen, the wound was kept open and wounds all healed with secondary intension. Hence, the healing scar was thick, cured? in and painless because of its cushioning effect. On the contrary primary closure of incision was performed in this reported series. Hence, scar tissue was thin and also painless. Primary closure was performed due to the availability of modern sensitive antibiotics and better anti-tubercular drugs. Negative suction drain was used routinely in reported cases because it provided better drainage of the wound. Wounds healed by four to six weeks on average with dressing changes twice a week. Weight bearing was allowed after approximate time of union of split calcaneum at 12 weeks.

Other modalities of management of chronic osteomyelitis of calcaneum exist. They are partial or subtotal calcanectomy, total calcanectomy and other flap coverage surgeries. Partial calcanectomy is an old but reasonably good surgical procedure. 
There are several reports recommending partial calcanectomy for chronic osteomyelitis of calcaneum with non healing ulcer, old fracture calcaneum. ${ }^{4,5}$ The success rate of this procedure is very high in our series with complete closure of all heel wounds and no signs of dehiscence.

Other studies also affirmed the role of partial resection of the os calcis and primary closure in the treatment of resistant large ulcers of the heel with or without osteomyelitis. ${ }^{6,7}$ Total calcanectomy is another surgery for eradication of infection and preservation of functional ability of lower limb after a refractory chronic calcaneal osteomyelitis. So trans tibial amputation may be avoided after total calcanectomy. ${ }^{8}$ So total calcanectomy is an excellent alternative for the eradication of infection, primary wound closure, and preservation of functional ambulation. But strength of muscles is reported to be decreased and ankle movement is reduced after total calcanectomy. ${ }^{8}$ Subtotal calcanectomy is a relatively simple procedure to perform. In the presence of adequate vasculature, it is a good alternative to below-the-knee amputation and the accompanying sequel even for patients with diabetic neuropathy. ${ }^{9}$ Studies suggest that resection of the major portion of the calcaneus does not prevent the patient from bearing weight on the foot and subtotal calcanectomy is superior to total calcanectomy because it provides a more stable foot. ${ }^{10,11}$ So excision of calcaneum to different extents as required in every different case could give expected result.

In a case report by Jerome, et al., in April, 2009, he clearly recommended the Gaenslen's technique for refractory cases of osteomyelitis or patients with a draining sinus centrally located on the plantar aspect of the heel due in part to its excellent functional result. $^{12}$

In 2009, E Wang, mentioned that the indication of the Gaenslen's split-heel technique would be useful for a number of different cases. These include chronic calcaneal osteomyelitis and refractory or recurrent cases and more extensive lesions within the calcaneus such as puncture-related cases with lesions near the plantar aspect of the calcaneus.
Although growth disturbance would be seen with successful use of this technique in some cases, an excellent functional and cosmetic result could be obtained in young children (5-11 years old) at midterm follow up. ${ }^{13}$

\section{Conclusion}

In this reported series, all three cases were treated by Gaenslen split heel approach. The incision made long enough for exposure of the diseased calcaneus. The chance of injury to the neurovascular bundle was insignificant. Splitting of the calcaneum aided us in exposure to reach inside the center of the calcaneus for thorough curettage of infected tissue. The incision was closed primarily. There is little scar tissue and it was thin and painless and not curled inwards..

No additional surgery was necessary for plastic repair of non healing ulcer. Muscle strength of lower limb was recovered fully in follow up. Ankle movement was regained to almost its full extent. It seems after almost four years of follow up that Gaenslen Split heel approach is an excellent, easy and safe way of management for chronic osteomyelitis of calcaneum with centrally located ulcer and treatment of calcaneal osteomyelitis of varying degrees.

\section{References}

1. Antoniou D, Conner AN. Osteomyelitis of the calcaneus and talus. JBJS 1974 56A: 338-45.

2. Gaenslen FJ. Split-heel approach in osteomyelitis of os calcis. JBJS 1931 13A: 759-772.

3. Broudy AS, Scott RD, Watts HG. The split-heel technique in the management of calcaneal osteomyelitis in children. Report of three cases. Clin Orthop Relat Res 1976 119: 202-205.

4. WoII TS, Beals RK. Partial calcanectomy for the treatment of osteomyelitis of the calcaneus. Foot and Ankle 1991 12: 31-34.

5. Crandall RC, Wagner FW Jr. Partial and total calcanectomy. A review of thirty-one consecutive cases over a ten-year period. JBJS 1981 63A: 152-155.

6. Horwitz T. Partial resection of the os calcis and primary closure in the treatment of resistant large ulcers of the heel with or without osteomyelitis of the os calcis. Clin Orthop 1972 84: 149-153. 
7. Martini M, Martini-Benkeddache Y, Bekhechi T, Daoud A. Treatment of chronic osteomyelitis of the calcaneus by resection of the calcaneus. A report of twenty cases. JBJS1974 56A: 542548.

8. Bragdon G, Baumhauer J. Total calcanectomy for the treatment of chronic osteomyelitis. Techniques Foot \& Ankle Surgery 2008 7(1): 52-55.

9. Baravarian B, Menendez MM, Weinheimer DJ, Lowery C, Kosanovich R, Vidt L. Subtotal calcanectomy for the treatment of large heel ulceration and calcaneal osteomyelitis in the diabetic patient. J Foot Ankle Surg 1999 38(5): 373-374.

10. Horwitz T. Partial resection of the os calcis and primary closure in the treatment of resistant large ulcers of the heel with or without osteomyelitis of the os calcis. Clin Orthop 1972 84: 149-153.

11. Wiltse LL, Bateman JG, Kase S. Resection of major portion of the calcaneus. Clin Orthop1959 13: 271-278.

12. Jerome JTJ, Varghese M, Sankaran B, Thomas S. Gaenslen's split heel incision for calcaneal osteomyelitis: A case report. The Foot and Ankle Online Journal 20092 (4): 3

13. Wang E, Zhao Q, Zhang L, Ji S, Li J. The split-heel technique in the management of chronic calcaneal osteomyelitis in children. J Pediatric Orthopaedics 2009 18(1): 23-27. 